IP Periodica Polytechnica Chemical Engineering

\author{
62(2), pp. 182-187, 2018 \\ https://doi.org/10.3311/PPch.10470 \\ Creative Commons Attribution (i)
}

RESEARCH ARTICLE

\section{The Effect of Foreign Fats on the Physical Properties of Anhydrous Milk Fat}

\author{
Tekla Izsó $^{1 *}$, László Somogyi ${ }^{1}$, Anita Soós ${ }^{1}$, Ildikó Zeke ${ }^{2}$
}

Received 05 January 2017; accepted after revision 25 April 2017

\begin{abstract}
Butter and anhydrous milk fat are considered valuable raw materials, therefore it is important to detect the presence of foreign fats and declare their purity. In this study, the authors compared the physical properties of pure anhydrous milk fat and its contaminated forms which were binary blends made with lard and palm fat. Tests with pulsed NMR and DSC were carried out ignoring any solvents or chemicals to observe melting and crystallization processes. Based on the results, small amounts (5-10 V/V\%) of lard or palm fat can modify milk fat's behavior in perceptible extent. Despite of this, a completely unknown fat cannot be identified by these methods only. However, with multiple replications and using statistical methods pNMR and DSC can be utilized for quality control purposes.
\end{abstract}

\section{Keywords}

milk fat, adulteration, lard, palm mid fraction, $p N M R, D S C$

\section{Introduction}

In the bakery and confectionery industry, the monitoring of fats' purity to prove that they are free from other fats as contaminants have high importance in ensuring a constant and proper level of quality. The presence of extraneous fat with unknown origin can cause noticeable changes and the producer cannot prepare for different behaviours, therefore the process cannot be controlled, especially if the contamination was deliberate - a so-called adulteration. Since butter and/or its often used form, anhydrous milk fat, are considered valuable raw materials due to their outstanding sensory properties; thus they are popular targets of adulteration. For economic reasons thus they are frequently blended with less expensive vegetable or other animal fats [1], thereby deceiving consumers or users.

In addition, milk fat is a very precious commodity product, has a highly complex fatty acid composition $[2,3]$ and is rich in short chain fatty acids [4]. Palmitic and myristic acids are located in sn-2 position in milk fat's triglycerides, which is one of its peculiarities $[5,6]$ and also has a characteristic crystallisation in $\beta^{\prime}$ form, due to the asymmetric molecules [7]. Compared to other fats, milk fat reaches slowly its final crystal structure hence the several and variously shaped triglycerides, which cause structural incompatibility and obstructed integration of triglycerides [8]. Another distinctness of milk fat is its two-step crystallisation mechanism with sigmoid shaped curves during isotherm solidification [9]. These typical attributes cannot be repressed by other fats mixed in minor ratios into milk fat, but can be modified by them: for example melting or crystallisation peaks becoming shifted. Physical behaviour, mainly solidification depends on the compatibility of various triglycerides in blends.

Ordinary detection methods for determining foreign fats in a pure fat base are focusing on the measurement of fatty acid or triglyceride composition. Bell and Gillatt demonstrates in their study [10] that these methods could not always provide sufficient information on their own. In the case of milk fat not only the complexity makes the detection difficult. Fatty acid composition diverges depending on the type of cattle, feeding and consequently the seasons, ripening stage of milk, advanced point of lactation period and additionally influenced by mastitis [11]. Because of factors 
listed above it is impossible to determine the contamination of dairy products with palm fat based on fatty acid composition [12] due to the two fats' high variability. Furthermore, the amount of certain fatty acids and triglycerides does not give guidance on how the contaminated fat will behave during processing, as these processes are strongly influenced by external conditions such as temperature, cooling rate, stirring, polymorphism etc.

Physical properties of blends containing milk fat and other oils/ fats can be well examined by measuring the blends' solid fat content as described in many studies [5, 7- 9, 13-16]. In these studies, generally the main target was to characterise the behaviour of milk fat blends containing $25-50 \%$ or more other fats, not the detection of small amounts of foreign fat. However, results suggest that using methods based on measuring solid fat content may be advantageous for other purposes.

Many researchers paid attention to the observation of changes caused by small amount (under 5\%) of foreign fat on milk fat's behaviour during melting and crystallisation and how the calorimetric curves modified. For example, palm fat in 2-35\% dosage affected the location and shape (height and width) of peaks on butter's melting curves as Tomaszewska-Gras identified it in a study on adulteration of butter. Quantitative analysis can be implemented as well with the calorimetric technique (DSC) as it was realized in context of the study [1]. Other researches also showed that DSC analysis combined with chemometrics is a suitable method to detect adulteration of foods containing various amounts of lipids (e.g. ham) [17]. Nurrulhidayah and his team also tested adulteration of butter [18], but butter containing lard in multiple proportions. According to their findings, different amounts of lard change butter's behaviour in $23-25{ }^{\circ} \mathrm{C}$ range in a detectable level as a result of adding $\beta$-crystals to the system.

Based on these, it is reasonable to observe physical phenomena to discover possible adulterations and also because of quality control aspects as well. Associated to this, we studied melting and solidification properties of milk fat containing foreign fat in 5-10\% ratio using simple and various methods which measure only solid fat content. Tests with pulsed NMR instrument served the aim to assess the behavioural changes of "contaminated" milk fat. Due to the promising results of the research reports, we also analysed milk fat-foreign fat mixtures' properties with DSC.

\section{Materials and methods}

\subsection{Materials}

Anhydrous milk fat was used for fat base (nominated as "M") which was blended with 5-10\% vegetable and animal fats and then mixed as binary systems for carrying out our research. Vegetable fat was palm mid fraction used as contaminant (nominated as "P"), and animal fat was commercially available lard (nominated as "L"). According to literature, butter and milk fat are commonly adulterated with lard and palm fat $[1,18,19]$.
Preparation of different mixtures was made by thawing the pure fats and measuring the appropriate ratios by a graduated cylinder and then stirring well the binary blends. Samples were stored in a refrigerator until the implementation of the tests. Compositions of the samples are shown in Table 1.

Table 1 Notation and composition of samples

\begin{tabular}{llll}
\hline Code of blend & $\begin{array}{l}\text { Amount of } \\
\text { milk fat } \\
(\mathbf{V} / \mathbf{V} \%)\end{array}$ & $\begin{array}{l}\text { Amount of } \\
\text { palm mid } \\
\text { fraction } \\
(\mathbf{V} / \mathbf{V} \%)\end{array}$ & $\begin{array}{l}\text { Amount of lard } \\
(\mathbf{V} / \mathbf{V} \%)\end{array}$ \\
\hline PM 10/90 & 90 & 10 & 0 \\
PM 5/95 & 95 & 5 & 0 \\
LM 10/90 & 90 & 0 & 10 \\
LM 5/95 & 95 & 0 & 5 \\
\hline
\end{tabular}

\subsection{Methods}

All processes were based on observing melting and crystallization properties. In addition, sample preparation only meant the thawing the samples, ignoring any solvents or chemicals.

\subsubsection{Solid fat content}

Solid fat content (SFC) of fats and oils can be determined by pulsed nuclear magnetic resonance (pNMR) which is a non-destructive method. Therefore, we used for this purpose Bruker Minispec 120 type pNMR instrument that was calibrated for measuring $\mathrm{SFC}$ in percentage (SFC\%).

\subsubsection{Solid fat content profile (melting)}

Solid fat content was measured in $5-45^{\circ} \mathrm{C}$ range based on the official AOCS method Cd 16-b-93 on nine different temperatures with three parallel samples for each temperature. The completely melted pure fats and their binary mixtures were poured into NMR-tubes in hot condition, and then samples were put in a refrigerator at least for an hour to stabilize spontaneously. Before the measurement itself, stabilization was followed by a 30-minute-long tempering session in thermostats on proper temperatures.

\subsubsection{Isothermal crystallization curves}

In this study we examined isotherm solidification in case of two different temperature stages with a modified method used by Campos et al. in 2002 [7]: cooling from $80^{\circ} \mathrm{C}$ to $10^{\circ} \mathrm{C}$ and from $80^{\circ} \mathrm{C}$ to $15^{\circ} \mathrm{C}$. For this method samples that already have been stabilized in the refrigerator were thawed in an $80^{\circ} \mathrm{C}$ thermostat for 30 minutes to delete crystal memory [15]. Solid fat content of samples cooled on two different temperatures were measured in every 3 minutes for 2 hours, while they reached the equilibrium stage. 


\subsubsection{Differential scanning calorimetry}

During melting, crystallization or even changes in crystalline form or structure, materials emit or absorb heat. Differential scanning calorimetry (DSC) is suitable to measure what temperatures pertain to these changes and also what thermal effects they are followed by [20].

For DSC analysis we thawed the blends and pure fats for ease of preparation, and then the $15-20 \mathrm{mg}$ of samples were weighed into aluminium vials ( $100 \mu \mathrm{l}$ size) on a digital scale. Before the measurement itself, stabilization occurred at room temperature. The study was carried out by Setaram evo DSC 131 type calorimeter with a temperature program that was chosen in accordance with solid fat content. The temperature variations applied to DSC scanning were the following. The sample was cooled from $20^{\circ} \mathrm{C}$ to $2{ }^{\circ} \mathrm{C}$ (rate, $1^{\circ} \mathrm{C} / \mathrm{min}$ ), kept at $0{ }^{\circ} \mathrm{C}$ for $10 \mathrm{~min}$, heated to $50{ }^{\circ} \mathrm{C}$ (rate, $1{ }^{\circ} \mathrm{C} / \mathrm{min}$ ), kept at $50^{\circ} \mathrm{C}$ for 10 min, cooled to $0^{\circ} \mathrm{C}$ (rate, $1{ }^{\circ} \mathrm{C} / \mathrm{min}$ ), kept at $0{ }^{\circ} \mathrm{C}$ for $10 \mathrm{~min}$ and heated to $20^{\circ} \mathrm{C}$ (rate, $5{ }^{\circ} \mathrm{C} / \mathrm{min}$ ). We selected a slow cooling process to facilitate the emergence of stable crystalline forms. Data collection was made in the heating phase $\left(0-50^{\circ} \mathrm{C}\right)$ when samples were completely melted and in the cooling phase (50$0^{\circ} \mathrm{C}$ ) when samples crystallized.

\section{Results and discussion}

\subsection{Results based on solid fat content}

\subsubsection{Solid fat content profile (melting)}

Solid fat contents of pure fats are absolutely different as shown on Fig. 1: palm mid fraction has the highest on every temperature, while lard has the lowest under $20^{\circ} \mathrm{C}$, in turn milk fat is between the two (on $5^{\circ} \mathrm{C} \mathrm{P}: 69,4 \%$, M: $51,7 \%$, L: $38,0 \%$ ).

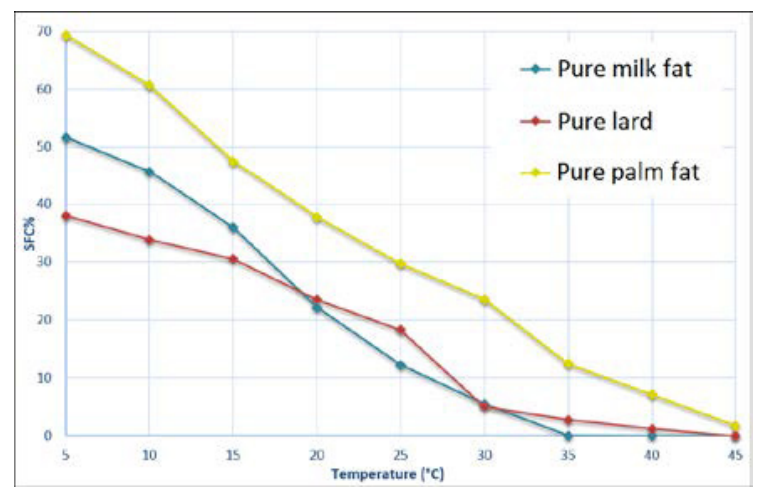

Fig. 1 The solid fat content of the pure samples at various temperatures

Above $20^{\circ} \mathrm{C}$, curves of lard and milk fat intersect, lard's exceeds milk fat's values. Results of "contaminated" milk fat samples are presented in Fig. 2.

$\mathrm{SFC} \%$ values of lard and palm mid fraction could be inferred from which direction the solid fat content of milk fat will change as a result of contaminants. According to this, palm fat hardens milk fat: differences among PM 95/5 and PM 90/10 samples are clearly visible at temperatures below $15^{\circ} \mathrm{C}$. Between pure lard's and milk fat's $\mathrm{SFC} \%$ values deviation is much slighter; therefore, the effect of lard is less evident. It was generally observed that the differences amid the curves are more prominent at lower temperatures, but this by itself does not clarify the contamination.

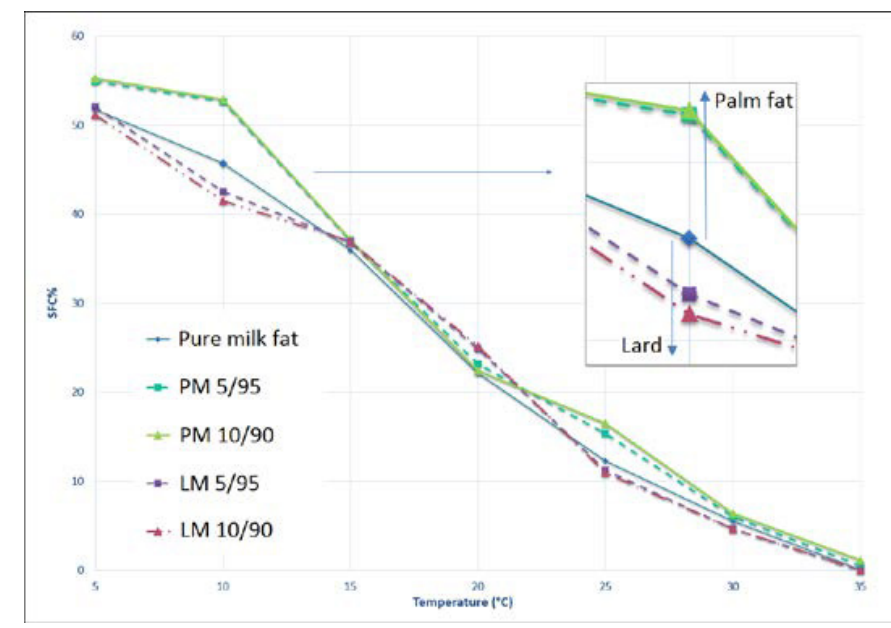

Fig. 2 The solid fat content of the contaminated samples at various temperatures

\subsubsection{Isothermal crystallization curves}

Solid fat content in function of time indicates how the fats will behave in case of isotherm crystallization. The ascent of curves, the time required for achieving equilibrium value, shape of the curves all refer to the crystallization mechanism that is unique to the fats. Fats also respond differently to changes in the degree of supercooling, so two final temperatures, $10^{\circ} \mathrm{C}$ and $15^{\circ} \mathrm{C}$ were selected for the analysis of solidification.

At $10^{\circ} \mathrm{C}$, maximum $\mathrm{SFC} \%$ values of LM 5/95 and LM 10/90 samples exceeded pure milk fat's maximums; however, LM 5/95 and LM 10/90 blends behaved almost the same way upon cooling relative to each other (Fig. 3). Milk fat completely separated from the other samples by its higher solid fat content at solidification to $15^{\circ} \mathrm{C}$ by the end of 2 hours, curves of the "contaminated" blends did not deviate from the others.

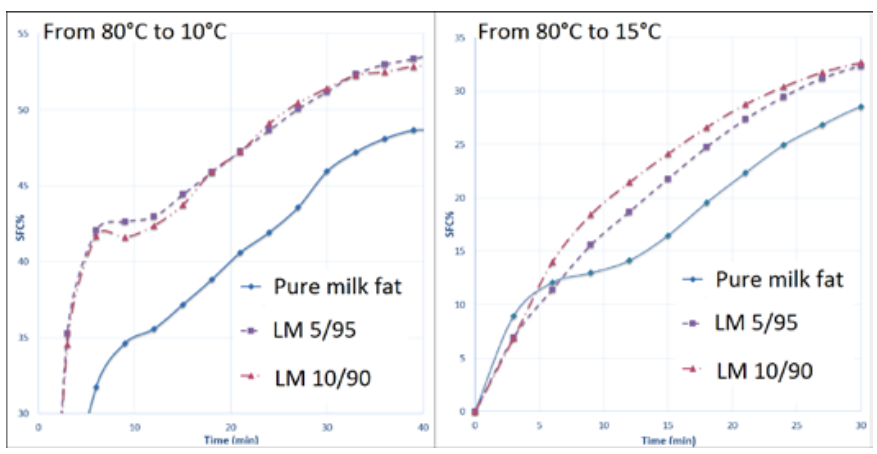

Fig. 3 Solidification of samples adulterated by lard

Palm mid fraction added to milk fat in small amounts caused less $\mathrm{SFC} \%$ than pure milk fat in contrast to what was expected as it can be seen on Fig. 4. In summary it can be said that if there is a two-step mechanism, it represents the dominance of milk fat, but if the sample contains some palm fat, the equilibrium $\mathrm{SFC} \%$ will be at lower values. 


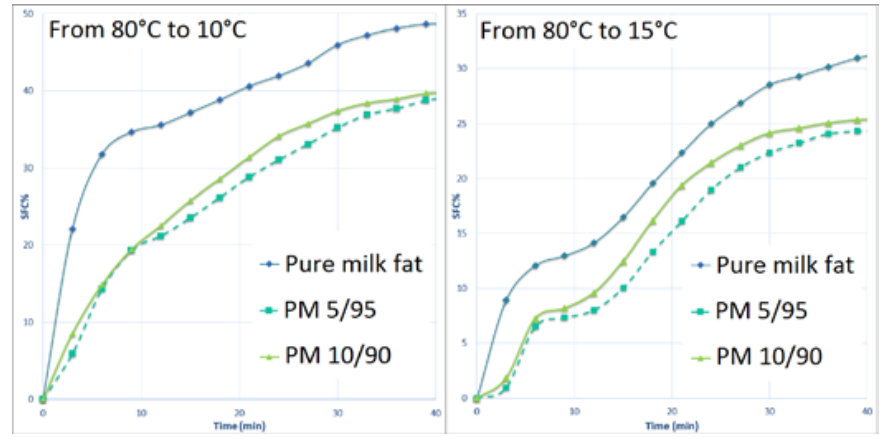

Fig. 4 Solidification of samples adulterated by palm fat

\subsection{Curves of melting and crystallization (DSC)}

Differential scanning calorimetry provides a great opportunity to distinguish fats from each other and moreover to determine them. However, it must be considered that the mixtures or in this case the "contaminated" samples' curves will evolve in light of how different fats' triglycerides that can be formed into larger units. The tested three fats' melting and crystallization mechanisms are quite individual: shape of curves, quantity and size of peaks, and their maximum temperatures are all substantially apart. At lower temperatures, the characteristics of milk fat are minor peaks at the beginning of the crystallization curve that was initiated by a short chain of fatty acids and BPP, BMS triglycerides. Lard always crystallizes instantaneously with one sharp peak which is attributed to the dominance of oleic acid. Palm fat crystallizes with a larger peak with a wider temperature range that could be caused by association of POP, POS, PLP and PPS, PPP triglycerides which have the ability of engagement, triggered by slow cooling. All three pure fats melted in several parts as a result of heating.

\subsubsection{Peak maximums}

Lard added to milk fat indicates a reduction of maximum temperatures, in the case of the first largest peak that crystallized. This phenomenon can be seen in Fig. 5, indicated by arrows. Decrease of peaks' maximum temperatures is not significant at first sight (M: $11.12^{\circ} \mathrm{C}, \mathrm{LM} 5 / 95: 11.075^{\circ} \mathrm{C}, \mathrm{LM}$ 10/90: $10.301{ }^{\circ} \mathrm{C}$ ), but the trend is obviously visible.

During the melting process (shown in the lower part of Fig. 5), lard modified shape and complexity of the peak occurring at $15-20^{\circ} \mathrm{C}$ range. Multifarious triglycerides in milk fat generate low, mid and high melting point fractions [1]. This complex composition intensifies when other fats are added.

DSC-analysis of milk fat samples containing palm fat eventuated melting curves, which did not show sufficiently well-defined transformations. Therefore, we rather focused on crystallization process.

Curves of crystallization (upper part of Fig. 6) offer more information about differences when milk fat is contaminated with palm mid fraction. The shifting of smaller peaks in the $15-20^{\circ} \mathrm{C}$ range towards palm fat can be observed on Fig. 6, specified by arrows. Gradual drift is examined in this case too; peak maximums are $16.147^{\circ} \mathrm{C}$ for $\mathrm{M}, 16.335^{\circ} \mathrm{C}$ for $\mathrm{PM} 5 / 95$ and $17.613^{\circ} \mathrm{C}$ for PM $90 / 10$ sample. Thus, because of palm fat the crystallization begins earlier. This may be due to the higher proportion of saturated and long chain fatty acid content of the palm fat (palm fat: $\mathrm{C} 16: 0+\mathrm{C} 18: 0=51.1 \%$, milk fat: $\mathrm{C} 16: 0+\mathrm{C} 18: 0=41.3 \%$ ), which is capable of crystallization at higher temperatures.

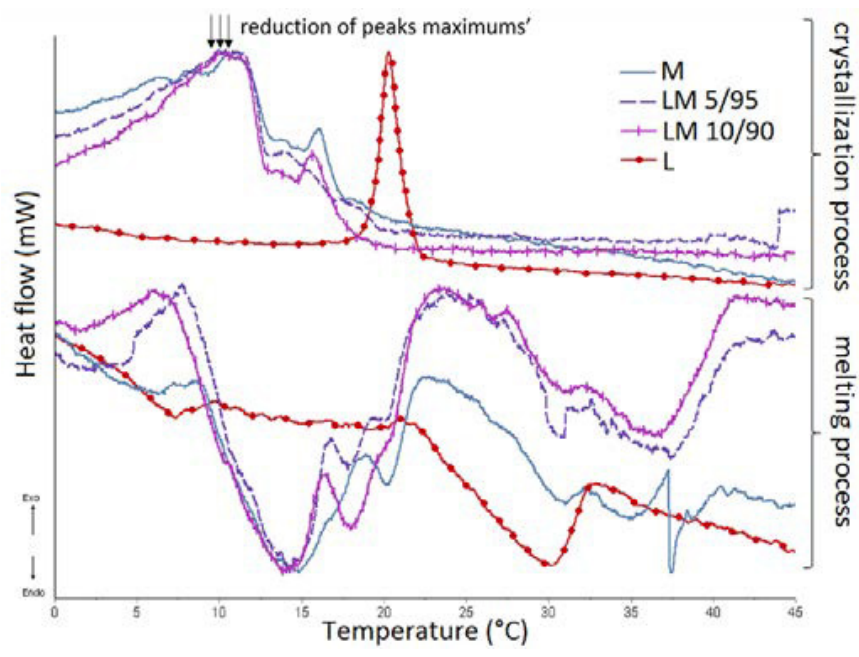

Fig. 5 Curves of LM 5/95 and LM 10/90 samples with the pure fats

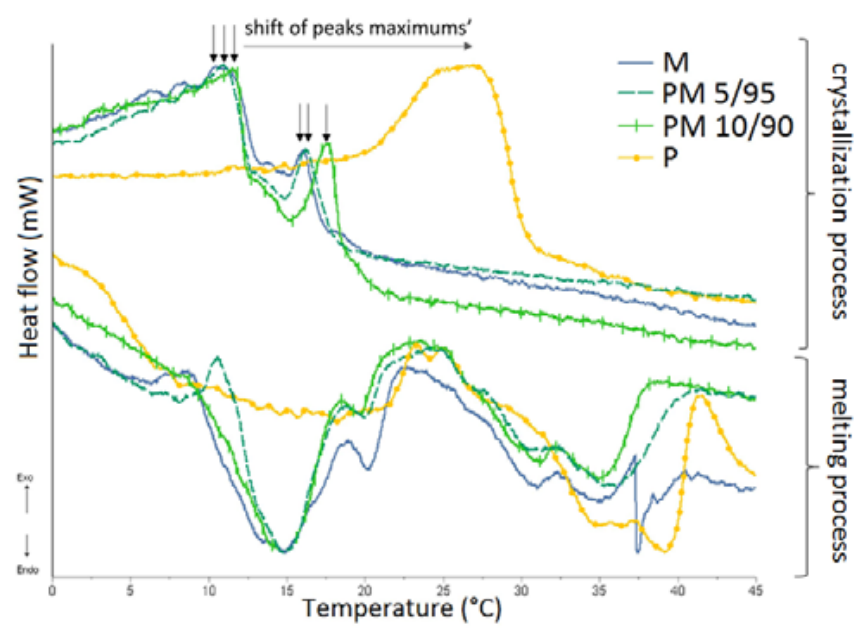

Fig. 6 Curves of PM 5/95 and P M 10/90 samples with the pure fats

\subsubsection{Enthalpy}

In the previous paragraphs, curves obtained from DSCanalysis were compared on the basis of the maximum temperature of peaks, as these data are independent of how the designation of peaks happened throughout the evaluation. The amount of heat $(\mathrm{J} / \mathrm{g})$ related to one transformation that is shown by the area enclosed by the baseline and the peak is also very informative. However, integration of peaks is calculated by the software that depends on how the area is chosen by the person who evaluated the results. For this reason, much altered outcomes can be obtained by the person conducting the evaluation [21]. 
Enthalpies of peaks are accumulated in case of mixtures, so differences are expected among the heat that accompany the melting/crystallization of pure and contaminated samples. In Table 2 enthalpies of peaks belonging to pure fats and mixtures containing 5-10\% palm fat or lard are shown.

Trends of changes in enthalpies refer to contamination. If the heat for milk fat's melting curve increases that definitely indicates adulteration or contamination. Enthalpy related to the first melting peak (temperature interval between $8^{\circ} \mathrm{C}$ to $22^{\circ} \mathrm{C}$ on Fig. 5) is influenced by a small amount of lard, while palm fat has impact on the second melting peak's (appearing at temperatures from $25^{\circ} \mathrm{C}$ to $38^{\circ} \mathrm{C}$ on Fig. 6) enthalpy values. A $5 \%$ contamination can be seen from these modifications.

Table 2 Enthalpy of peaks belonging to melting and crystallization of samples.

\begin{tabular}{llll}
\hline $\begin{array}{l}\text { Code of } \\
\text { sample }\end{array}$ & $\begin{array}{l}\text { Crystallization } \\
\text { heat }(\mathbf{J} / \mathbf{g})\end{array}$ & $\begin{array}{l}\text { Heat of melting } \\
\text { Peak 1 (J/g) }\end{array}$ & $\begin{array}{l}\text { Heat of melting } \\
\text { Peak 2 (J/g) }\end{array}$ \\
\hline M & -22.242 & 23.498 & 8.998 \\
P & -22.292 & 25.986 & 24.873 \\
L & -22.877 & 7.305 & 14.878 \\
PM 5/95 & -20.591 & 17.21 & 15.419 \\
PM 10/90 & -21.515 & 21.61 & 15.617 \\
LM 5/95 & -20.901 & 27.572 & 16.066 \\
LM 10/90 & -22.633 & 30.66 & 14.743 \\
\hline
\end{tabular}

\subsubsection{The shape of the peaks}

When blends containing the same amount of various contaminants were compared, we perceived that the different foreign fats caused other types of changes in the shape of the melting curves.

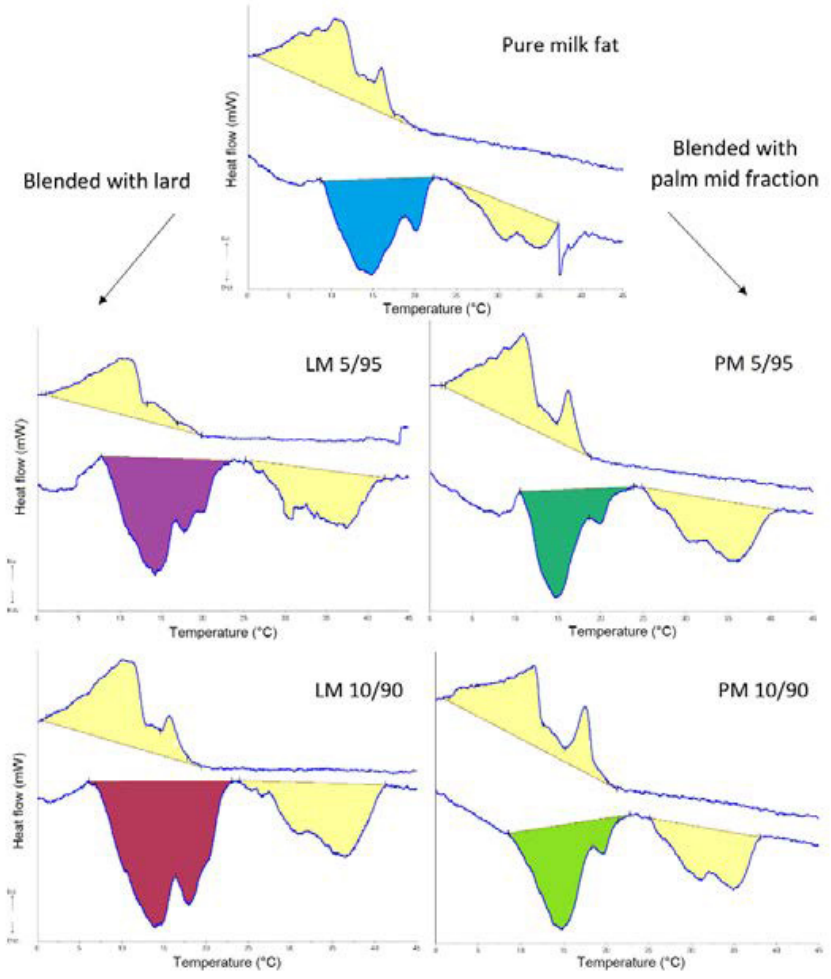

Fig. 7 Curves of pure milk fat and its various contaminated forms
Peaks appearing in the lower temperature ranges have a dissimilar shape affected by variant foreign fats as it clearly can be seen on Fig. 7.

Lard was thinning the first characteristic melting peak of milk fat (peak performing between $8^{\circ} \mathrm{C}$ and $22^{\circ} \mathrm{C}$ ), while palm fat had widened and enlarged this peak (Fig. 7). The typical changes provide an opportunity to establish the fact of impurity, in addition to the distinction between the contaminants.

\section{Conclusions}

The aim of this study was to assess potential techniques, which while neglecting solvents are only based on the observation of fats physical properties while suitable for detection of contamination. Measurements were carried out using milk fat as pure fat whereas lard and palm fat were the contaminants in the sample mixtures.

Lard or palm fat added in small amounts $(5-10 \mathrm{~V} / \mathrm{V} \%)$ to milk fat have modified milk fat's behaviour as it was clearly visible during our experiments. All curves - SFC and DSC as well, revealed shifts, changes on shape, and variant values to a certain extent. Transformation of physical behaviour is attributed to unique triglyceride composition, which causes altered 3D-structure when triglycerides are built into it. Molecules from different fats aggregate together are making crystal structure according to their compatibility [22]. Therefore, foreign fats do not creating new peaks, only affect the location of peaks or shape of the curves.

Changes compared to pure milk fat were not outstanding but perceptible; moreover, with multiple replications and using statistical methods these can be utilized for quality control purposes.

Methods used in this study have revealed that it is possible to determine this kind of purity of fats based on easyto-use instruments such as low-resolution pNMR and DSC. Their applicability has limitations, for example a completely unknown fat cannot be identified by these methods only, especially from the aspect that these three fats' compositions fluctuate in a wide range.

Nevertheless, they would be excellent for quality assurance goals, if the producers use their commodity as an etalon. Manufacturing plants, if that is possible, should not rotate their suppliers and ingredients, but even with reliable suppliers, there are also differences in the quality of various batches. Therefore, pure materials should be tested by these methods more than once to have an appropriate basis with a defined range about standard deviation of samples for comparison. Then the pure fats can be regarded as standards and new incoming raw materials can be measured to them.

In addition to commodity verification, methods examined in this study can be useful if a plant is forced to exchange raw materials or a new development is carried out, as these methods are based on the physical behaviour of fats. 


\section{References}

[1] Tomaszewska-Gras, J. "Rapid quantitative determination of butter adulteration with palm oil using DSC technique." Food Control. 60, pp. 629635. 2016. https://doi.org/10.1016/j.foodcont.2015.09.001

[2] Jensen, R. G. "The composition of bovine milk lipids: January 1995 to December 2000." Journal of Dairy Science. 85(2), pp. 295-350. 2002. https://doi.org/10.3168/jds.S0022-0302(02)74079-4

[3] Swern, D. "Bailey’s Industrial Oil and Fat Products." In: O’Brian (ed.) 2009: Fats and Oils Formulating and Processing for Applications. CRC Press, 1979.

[4] Firestone, D. F. "Physical and Chemical Characteristics of Oils, Fats and Waxes." AOCS Press, Champaign, Illinois USA. 1999.

[5] Lopez, C., Bourgaux, C., Lesieur, P., Riaublanc, A., Ollivon, M. "Milk fat and primary fractions obtained by dry fractionation -Chemical composition and crystallisation properties." Chemistry and Physics of Lipids. 144(1), pp. 17-33. 2006.

https://doi.org/10.1016/j.chemphyslip.2006.06.002

[6] Rodrigues, J. N., Gioielli, L. A. "Chemical interesterification of milk fat and milk fat-corn oil blends." Food Research International. 36(2), pp. 149-159. 2003. https://doi.org/10.1016/S0963-9969(02)00130-8

[7] Campos, R., Narina, S. S., Marangoni, A. G. "Effect of cooling rate on the structure and mechanical properties of milk fat and lard." Food Research International. 35(1), pp. 971-98. 2002.

https://doi.org/10.1016/S0963-9969(02)00159-X

[8] Van Aken, G. A., Visser, K. A. "Firmness and Crystallization of Milk Fat in Relation to Processing Conditions." Journal of Dairy Science. 83(9), pp. 1919-1932. 2000. https://doi.org/10.3168/jds.S0022-0302(00)75067-3

[9] Herrera, M. L., de León Gatti, M., Hartel, L. W. "A kinetic analysis of crystallization of a milk fat model system." Food Research International. 32(4), pp. 289-298. 1999 https://doi.org/10.1016/S0963-9969(99)00083-6

[10] Bell, J. R., Gillatt, P. N. "Standards to ensure the authenticity of edible oils and fats." Food, Nutrition and Agriculture. 72(6), pp. 29-35. 1994.

[11] Csapó J., Csapóné Kiss, Zs. "Tej és tejtermékek a táplálkozásban." ( Milk and other dairy products in human nutrition.) Mezőgazda Kiadó Kft., Budapest. 2002. (in Hungarian)

[12] Azadmard-Damirchi, S., Torbati, M. "Adulterations in some edible oils and fats and their detection methods." Journal of Food Quality and Hazards Control. 2, pp. 38-44. 2015.
[13] Nor Aini, I. "Effects of Tempering on Physical properties of Shortenings Based on Binary Blends of Palm Oil and Anhydrous Milk Fat During Storage." In: Widlak, N., Hartel, R., Narina, S. (eds.) Crystallization and Solidification Properties of Lipids. (pp. 42-52.) AOCS Press, Champaig, Ill. 42-52. 2001.

[14] Shen, Z., Birkett, A., Augustin, M. A., Dungey, S., Versteeg, C. "Melting Behavior of Blends of Milk Fat with Hydrogenated Coconut and Cottonseed Oils." Journal of the American Oil Chemists 'Society. 78(4), pp. 387-394. 2001. https://doi.org/10.1007/s11746-001-0273-4

[15] Soós, A. "Effect of Vegetable Fats on the Physical Properties of Animal Fats." PhD Thesis, Corvinus University of Budapest. https://doi.org/10.14267/phd.2014045

[16] Wright, A. J., McGauley, S. E., Narine, S. S., Willis, W. M., Lencki, R. W., Marangoni, A. G. "Solvent effects on the crystallization behavior of milk fat fractions." Journal of Agricultural and Food Chemistry. 48(4), pp. 1033-1040. 2000. https://doi.org/10.1021/jf9908244

[17] Bayés-García, L., Tres, A., Vichi, S., Calvet, T., Cuevas-Diarte, M. A., Codony, R., Boatella, J., Caixach, J., Ueno, S., Guardiola, F. "Authentication of Iberian dry-cured ham: New approaches by polymorphic fingerprint and ultrahigh resolution mass spectrometry." Food Control. 60, pp. 370-377. 2016. https://doi.org/10.1016/j.foodcont.2015.07.047

[18] Nurrulhidayah, A. F., Arieff, S. R., Rohman, A., Amin, I., Shuhaimi, M., Khatib, A. "Detection of butter adulteration with lard using differential scanning calorimetry." International Food Research Journal. 22(2), pp. 832-839. 2015.

[19] Rebechi, S. R., Vélez, M. A., Vaira, S., Perotti, M. C. "Adulteration of Argentinean milk fats with animal fats: Detection by fatty acids analysis and multivariate regression techniques." Food Chemistry. 192, pp. 1025-1032. 2016. https://doi.org/10.1016/j.foodchem.2015.07.107

[20] Zeke, I. Cs. "Investigation of the stability of frozen food emulsions." PhD Thesis, Corvinus University of Budapest. 2015. https://doi.org/10.14267/phd.2015016

[21] Foubert, I., Dewettick, K., Vanrolleghem, P. A. "Modelling of the crystallization kinetics of fats." Trends in Food Science \& Technology. 14(3), pp. 79-92. 2003. https://doi.org/10.1016/S0924-2244(02)00256-X

[22] Narine, S. S., Marangoni, A. G. "Microscopic and rheological studies of fat crystal networks." Journal of Crystal Growth. 198-199(Part 2), pp. 1315-1319. 1999. https://doi.org/10.1016/S0022-0248(98)01016-1 